\title{
ESTUDO DOS ÍNDICES DE RETENÇÃO E REPROVAÇÃO NOS CURSOS DE ENGENHARIA DO CAMPUS CAMPOS CENTRO DO INSTITUTO FEDERAL FLUMINENSE
}

Leonardo Carneiro Sardinha - lcs@iff.edu.br

Maurício Gonçalves Ferrarez-mgferrarez@iff.edu.br

Flávia Peixoto Faria-fpfaria@iff.edu.br

Luis Mauricio Monteiro Tavares Guedes-lmauricio@iff.edu.br

Simone Souto da Silva Oliveira - souto@iff.edu.br

Luilcio Silva de Barcellos-lsb@iff.edu.br

Vantelfo Nunes Garcia-vantelfo.garcia@iff.edu.br

Odino Ferreira Neto-odino.neto@iff.edu.br

Juliana Santos Barcellos Chagas Ventura-jchagas@iff.edu.br

Alex Cabral Barbosa-alex.barbosa@iff.edu.br

Douglas de Jesus Vitoi Fonseca - douglas.fonseca@iff.edu.br

Luiz,Gustavo Lourenço Moura-gustavo@iff.edu.br

Instituto Federal Fluminense - RJ

Rua Dr. Siqueira, 273 - Parque Dom Bosco

28030-130 - Campos dos Goytacazes - Rio de Janeiro

Resumo: O presente trabalho apresenta os primeiros resultados de um estudo sobre a retenção dos estudantes dos cursos de Bacharelado em Engenharia de Controle e Automação, Engenharia Elétrica e Engenharia de Computação. A pesquisa tem como objetivo desenvolver uma metodologia de avaliação e controle do problema de retenção (e por conseguinte a evasão) discente das engenharias no campus Campos Centro do Instituto Federal Fluminense. $O$ instrumento da presente pesquisa na sustentação metodológica foi um questionário elaborado por uma equipe multidisciplinar sob laboriosas pesquisas acadêmicas. A análise estatística da base de dados foi de cunho descritivo. O estudo proporcionou importantes discussões acerca do processo de ensino e aprendizagem dos estudantes, culminando em uma proposta de ações que possam subsidiar políticas educacionais que contribuam para um maior sucesso acadêmico dos alunos.

Palavras-chave: Retenção. Reprovação. Engenharia. 


\section{INTRODUÇÃO}

A democratização do acesso à universidade é um movimento que cada vez mais ganha adeptos e conquistas, pois é vista como possibilidade de mudanças nas relações de poder que permeiam diversos espaços sociais. Um referencial para a busca da valorização pessoal é o acesso à Universidade, contribuindo principalmente na formação de um profissional com autonomia de pensamento, influenciando sua cultura, sua ética e na sua capacidade de solucionar problemas.

A eficiência de um curso pode ser percebida, dentre outros fatores, como o produto gerado em relação ao número de matriculados e o de formados no tempo mínimo previsto para a sua conclusão (SILVA; RODRIGUES; BRITO, 2014) e os indicadores de insucesso escolar devem ser constantemente analisados pelas Instituições de Ensino Superior (IES), a fim de delinear metas sobre o desempenho educacional.

A reprovação, a retenção e a evasão constituem os pilares do "desperdício escolar" e provocam prejuízos significativos nos aspectos econômicos, sociais e humanos, independentemente do nível de educação.

A reprovação com a consequente retenção ou evasão é um problema complexo e pode ser a soma de vários fatores que influenciaram na decisão do aluno de permanecer ou não no curso.

A reprovação caracteriza-se pelo insucesso dos estudantes nos componentes curriculares, enquanto, a retenção é a permanência excessiva em um curso, no qual o aluno, por diversos motivos, leva um tempo maior para concluí-lo do que aquele planejado no respectivo projeto pedagógico de curso (BRASIL, 2014; CISLAGHI, 2008).

Os estudos apontam que há perdas para todos os envolvidos no processo e as classificam da seguinte forma: perdas para o aluno, para as instituições, sociedade e para o país (AMARAL, 2013). Neste aspecto, é importante que as instituições reúnam informações consistentes anteriores ao ingresso do aluno na universidade, no decorrer do curso e no momento do abandono. Tais informações podem auxiliar na recuperação e manutenção do aluno no curso.

Os dados da situação acadêmica referentes aos cursos de Bacharelado em Engenharia de Controle e Automação e Engenharia, disponíveis na Plataforma Nilo Peçanha, revelam que a retenção no Instituto Federal Fluminense campus Campos Centro é de 26,30\% superando à retenção de 16,28\% registrada em âmbito nacional por outros Institutos Federais e Centros Federais de Educação Tecnológica Celso Suckow da Fonseca (Tabela 1). Os outros cursos de Engenharia formaram a primeira turma no semestre 2019.2, logo não apresentam dados de retenção na Plataforma Nilo Peçanha.

Tabela 1 - Situação acadêmica, ano base 2018, do curso de Engenharia de Controle e Automação no Brasil (IFs e CEFETs) e situação acadêmica do curso de Engenharia de Controle e Automação no IFFluminense campus Campos Centro.
Situação da Matrícula Engenharia de Controle e Automação -
Brasil (IFs e CEFETs)
Engenharia de Controle e Automação - IFF campus Campos Centro

\begin{tabular}{|l|c|c|}
\hline Em Fluxo & $67,94 \%$ & $61,05 \%$ \\
\hline Retido & $16,28 \%$ & $26,30 \%$ \\
\hline Concluída & $3,56 \%$ & $7,13 \%$ \\
\hline Integralizada & $0,82 \%$ & $0,00 \%$ \\
\hline Abandono & $4,91 \%$ & $0,48 \%$ \\
\hline Cancelada & $0,85 \%$ & $0,24 \%$ \\
\hline Transferência & $0,72 \%$ & $0,48 \%$ \\
\hline Externa & $4,92 \%$ & $4,51 \%$ \\
\hline Desligado & & \\
\hline
\end{tabular}

Fonte: http://resultados.plataformanilopecanha.org/2019/ 
Nessa perspectiva, levando-se em conta os fatores supracitados, a Direção de Ensino dos Cursos Bacharelado do Instituto Federal Fluminense do campus Campos Centro pensou uma forma de se identificar, estudar e trabalhar as diversas variáveis que interferem de forma direta e indireta na retenção dos cursos de engenharia. Foi criado um Grupo de Trabalho que tinha como objetivo atuar na problemática da retenção fazendo um diagnóstico e preparando metodologias para identificação e tratamento destas variáveis.

Inicialmente foi feito pela Direção de Ensino uma apresentação bem sucinta aos membros do grupo (Professores e Coordenadores - Áreas de Matemática e Física) buscando informar através de dados extraídos do Sistema Acadêmico um panorama sobre os índices de reprovação.

Para atingir este objetivo, traçou-se como ação afirmativa proceder uma investigação dos principais referenciais teóricos sobre a evasão/retenção de alunos de cursos de graduação, que permitisse identificar as causas relatadas para estes processos. Todas estas informações possíveis de serem adquiridas foram extraídas de um questionário criado ao longo das reuniões pelos membros deste Grupo de Trabalho. A proposta do questionário era buscar ter a clareza da conjuntura na qual os alunos se encontravam.

O presente estudo revela os resultados preliminares de uma pesquisa concernente à retenção dos discentes dos cursos de Bacharelados de Engenharia de Controle e Automação, Engenharia Elétrica e Engenharia de Computação considerando como parâmetro os cursistas das disciplinas do ciclo básico no segundo período de 2018, analisando somente as disciplinas na esfera da Matemática e Física, que possuem um expressivo impacto na retenção.

\section{METODOLOGIA}

O instrumento da presente pesquisa na sustentação metodológica foi um questionário elaborado por uma equipe multidisciplinar sob laboriosas pesquisas acadêmicas gerando um ciclo de discussões e reflexões concernentes à temática deste presente estudo e desencadeou o mecanismo-questionário que proporcionou a coleta dos dados. Nesta pesquisa foram considerados alguns aspectos, por exemplo, a influência do curso quanto à atuação profissional, a continuidade dos estudos, a avaliação referente à formação recebida, a interiorização das instituições, a permanência escolar, os fatores que influenciam a escolha dos cursos, dentre outros. Para melhor compreensão das perguntas, a aplicação do citado questionário foi presencial, com um professor do curso esclarecendo, se ocorressem, dúvidas na interpretação das mesmas. Ressalta-se que sempre se primou pela privacidade, veracidade e ética, ou seja, não sendo obrigatório aos discentes se identificarem ao preencher o questionário.

O questionário foi aplicado aos alunos cursantes de disciplinas do $1^{\circ}$ ao $4^{\circ}$ período dos cursos de Bacharelado em Engenharia, sendo que o mesmo foi respondido por 75 alunos do curso de Engenharia de Controle e Automação, 54 alunos da Engenharia de Computação e 67 alunos da Engenharia Elétrica. As respostas obtidas neste questionário permitiram uma avaliação das ações realizadas pelo alunado retido nas disciplinas em questão, possibilitando conhecer a situação dos mesmos e assim, promover dentro da instituição, discussões em torno do processo de ensino aprendizagem dos estudantes, culminando numa proposta de ações que possam subsidiar políticas educacionais necessárias, a partir dos dados obtidos.

A análise estatística da base de dados foi de cunho descritivo, isto é, que cuida basicamente da descrição dos dados, sem estabelecimentos de testes de hipóteses sobre o conjunto estudado. O método estatístico utilizado constou das cinco seguintes etapas (TRIOLA, 2011): 1- Coleta de dados (questionários); 2- Avaliação os dados (visualização dos dados e análise dos mesmos em relação à pertinência das respostas ao estudo); 3- Apuração dos dados (soma e organização, 
escolhendo a melhor forma de apresentar os dados obtidos); 4- Apresentação dos dados (tabelas e gráficos); 5- Análise dos dados (interpretação descritiva).

\section{RESULTADOS}

Em relação ao uso da biblioteca (Figuras 1, 2 e 3), uma porcentagem maior de alunos aprovados nos cursos de Engenharia Elétrica e Engenharia de Computação afirmou utilizar a biblioteca com maior frequência. Entretanto, no curso de Engenharia de Controle e Automação, uma porcentagem maior de alunos reprovados respondeu que utiliza a biblioteca com maior frequência.

Figura 1 - Utilização da biblioteca pelos alunos aprovados e reprovados do curso de Engenharia de Controle e Automação.

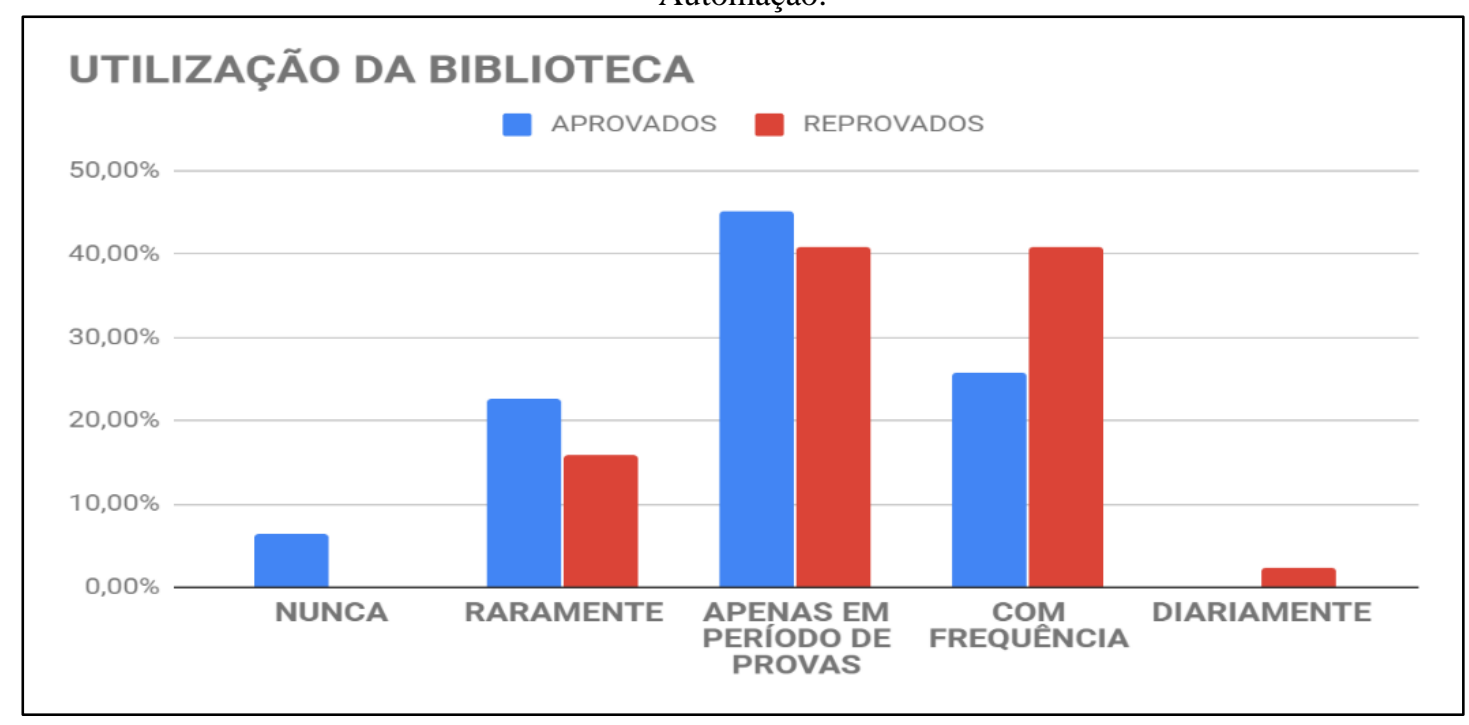

Fonte: Elaborado pelos autores (2020)

Figura 2 - Utilização da biblioteca pelos alunos aprovados e reprovados do curso de Engenharia Elétrica.

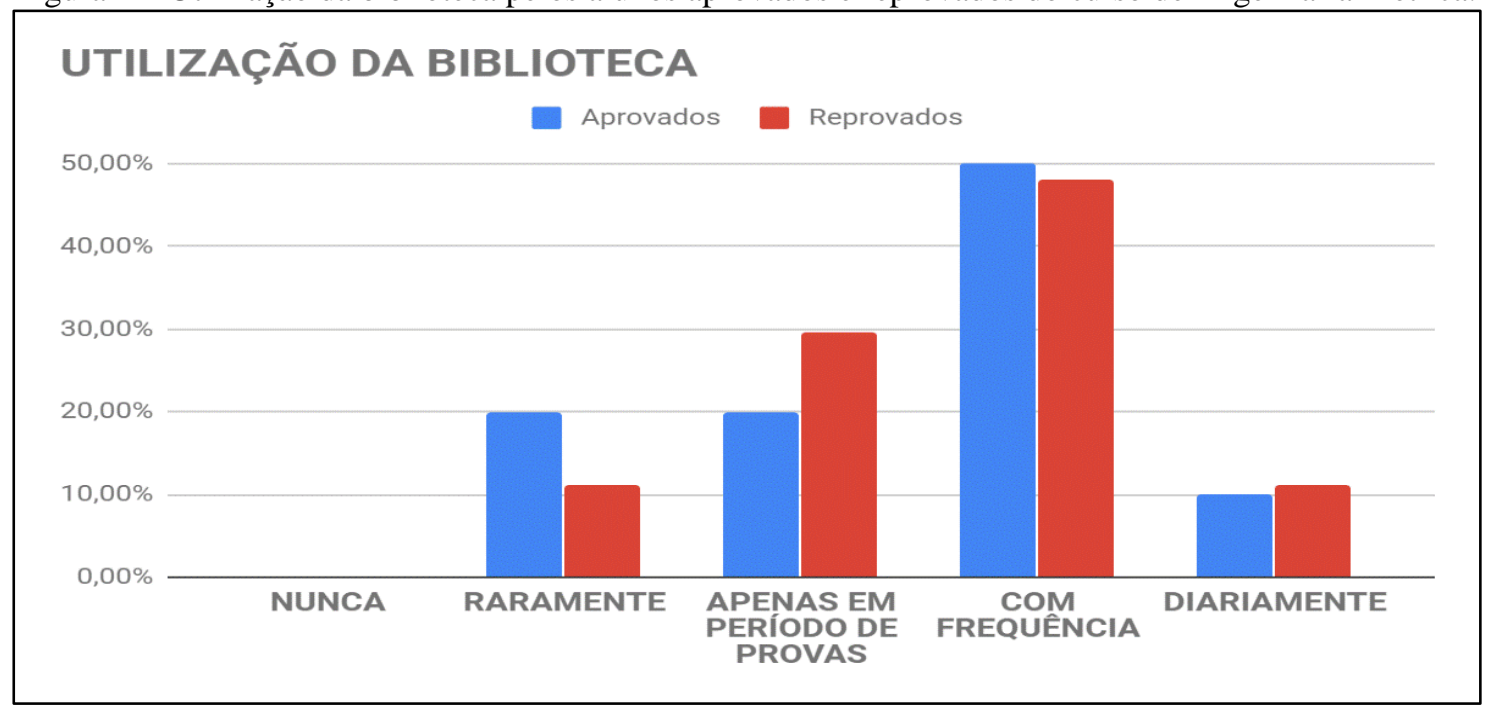

Fonte: Elaborado pelos autores (2020). 
"Os desafios para formar hoje o engenheiro do amanhã"

Figura 3 - Utilização da biblioteca pelos alunos aprovados e reprovados do curso de Engenharia de Computação.

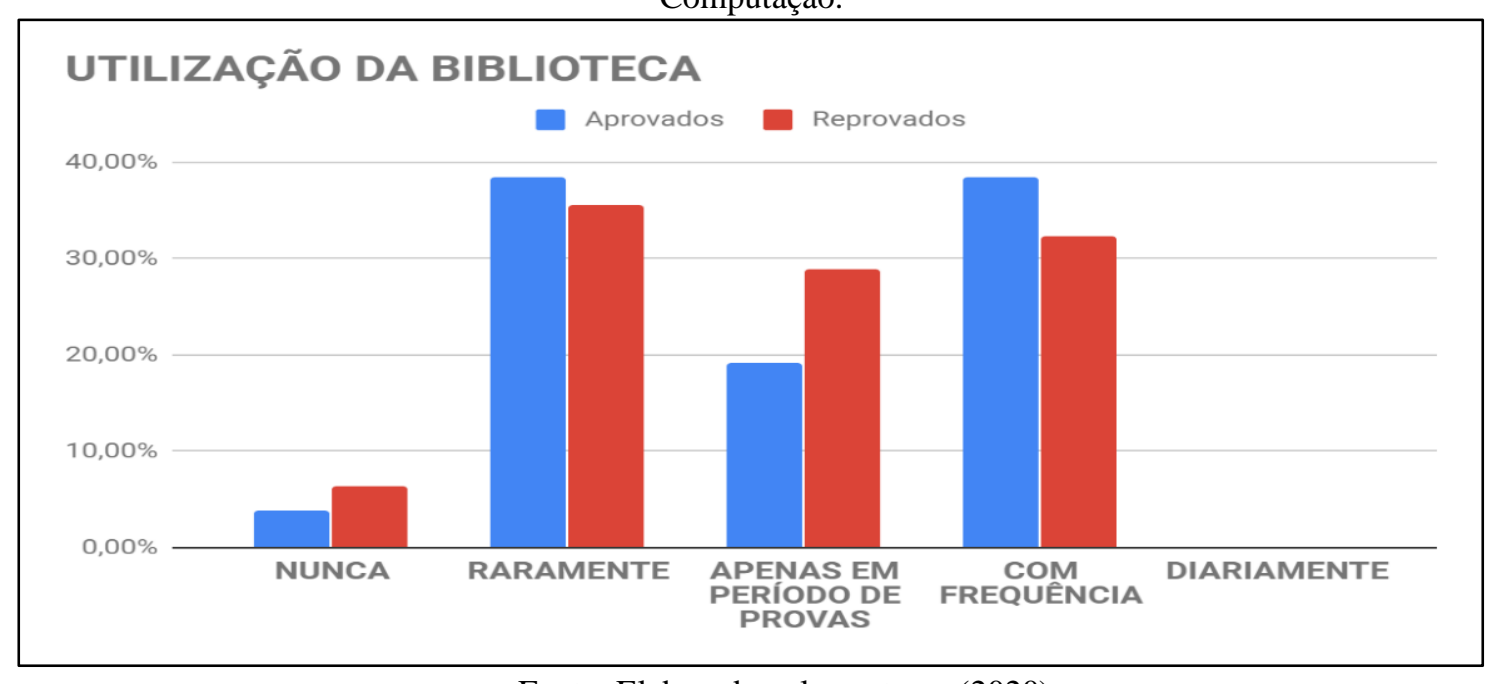

Fonte: Elaborado pelos autores (2020).

Em relação aos instrumentos mais usados para aprofundar os conhecimentos (Figuras 4, 5 e 6), uma porcentagem maior de alunos reprovados nos três cursos afirmaram utilizar videoaulas. A respeito de anotações manuais, nos cursos de Engenharia de Controle e Automação e Engenharia Elétrica, uma taxa maior dos alunos pesquisados aprovados afirma usar este material de estudo. Em relação aos livros-texto, nos três cursos pesquisados, houve um maior percentual de alunos aprovados que afirmaram utilizar esse recurso para aprofundar o conhecimento.

Figura 4 - Materiais mais utilizados pelos alunos do curso de Engenharia de Controle e Automação para aprofundar o conhecimento.

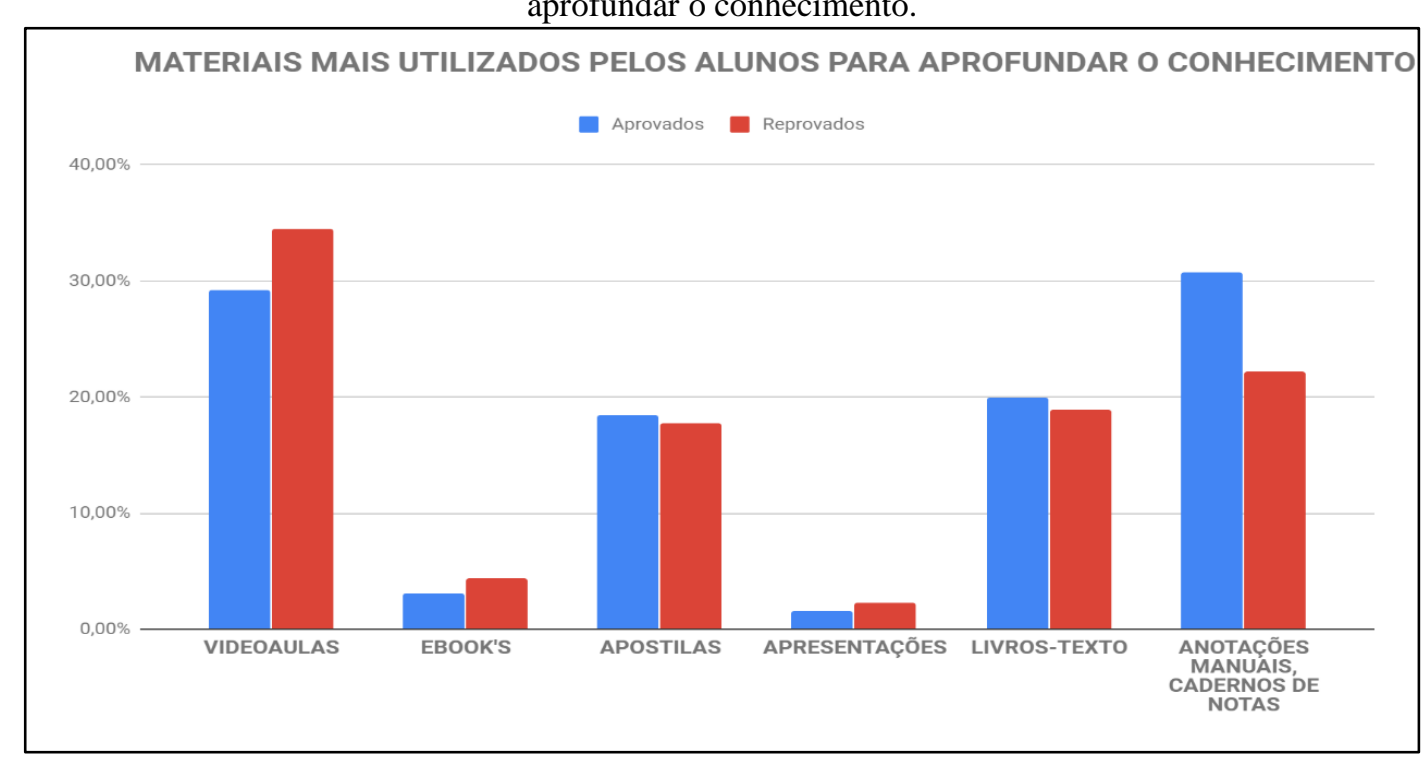

Fonte: Elaborado pelos autores (2020). 
"Os desafios para formar hoje o engenheiro do amanhã"

Figura 5 - Materiais mais utilizados pelos alunos do curso de Engenharia de Controle e Automação para aprofundar o conhecimento.

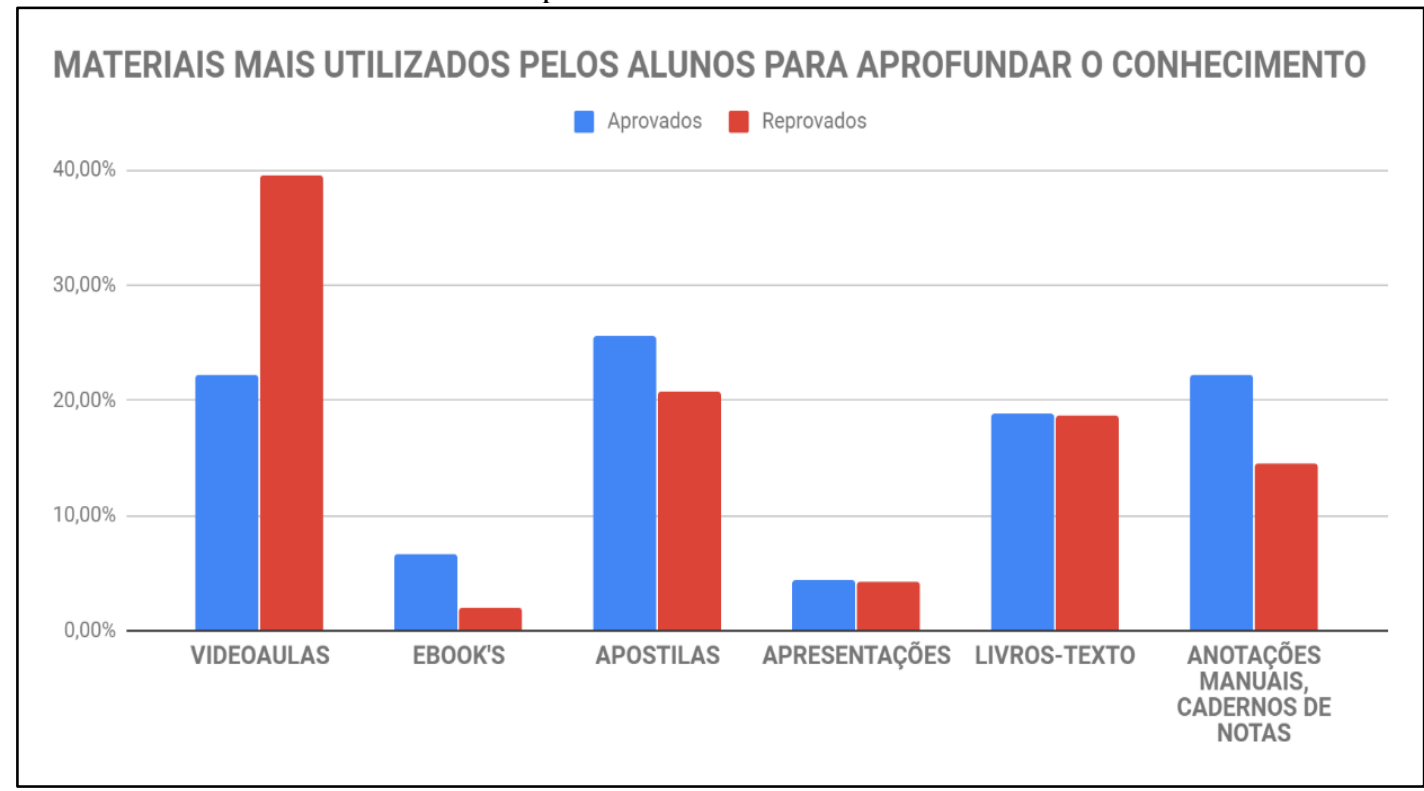

Fonte: Elaborado pelos autores (2020).

Figura 6 - Materiais mais utilizados pelos alunos do curso de Engenharia de Computação para aprofundar o conhecimento.

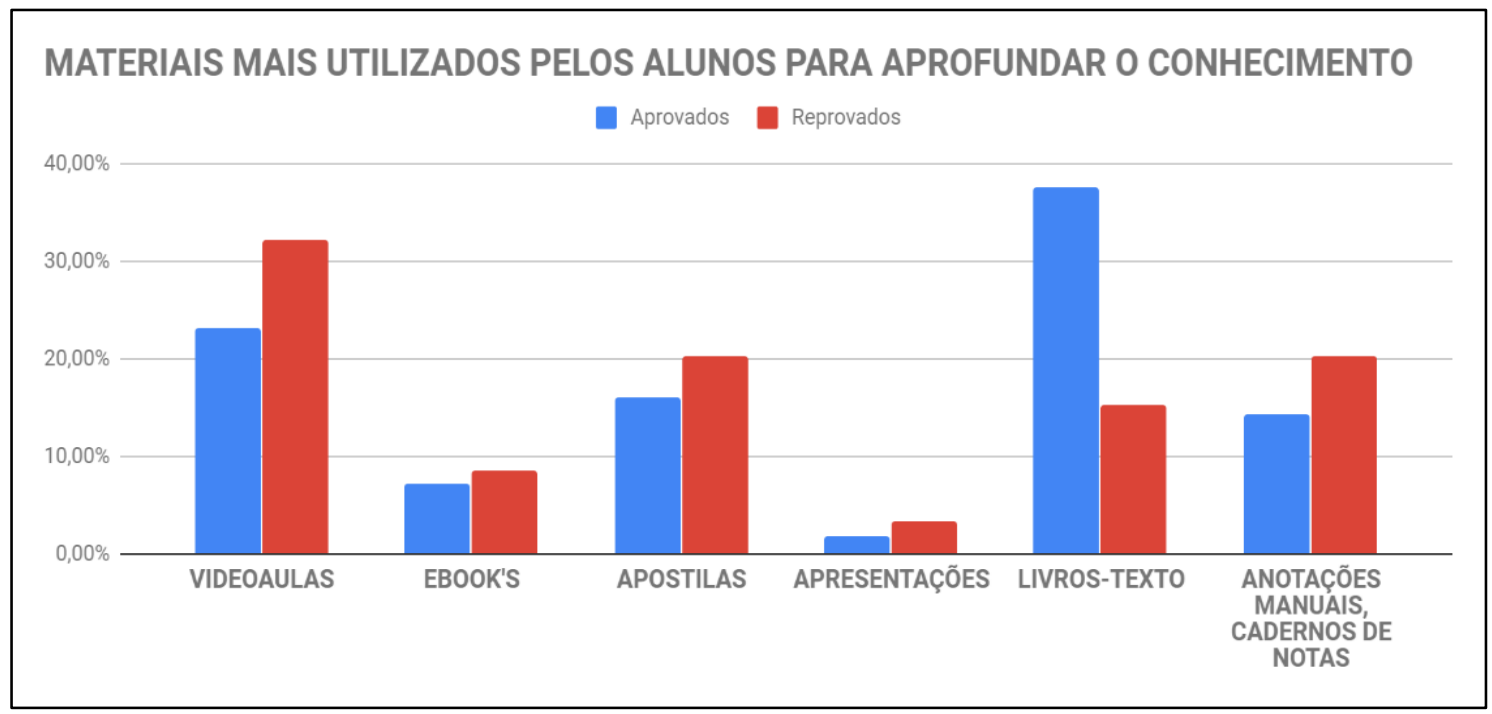

Fonte: Elaborado pelos autores (2020).

As maiores dificuldades na vida acadêmica apontadas (Figuras 7, 8 e 9), tanto por alunos aprovados quanto reprovados, nos três cursos, foram falta de autonomia ${ }^{1}$, falta de tempo e ausência de pré-requisitos ${ }^{2}$.

\footnotetext{
${ }^{1}$ Compreende-se autonomia como o fato de decidir por si, isto é, a capacidade de compreendermos o que é melhor para nós mesmos e, então, implementar nossas decisões. Autonomia significa poder rever nossos caminhos e decidir por outros, caso necessário.

${ }^{2}$ Referem-se aos conhecimentos construídos ao longo da educação básica.
} 


\section{COBENCE (C) COBENGE 2020 e III Simpósio Internacional de Educação em Engenharia
da ABENGE}

"Os desafios para formar hoje o engenheiro do amanhã"
O1 a 03 de dezembro Evento On-line

Figura 7 - Maiores dificuldades na vida acadêmica curso de Engenharia de Controle e Automação.

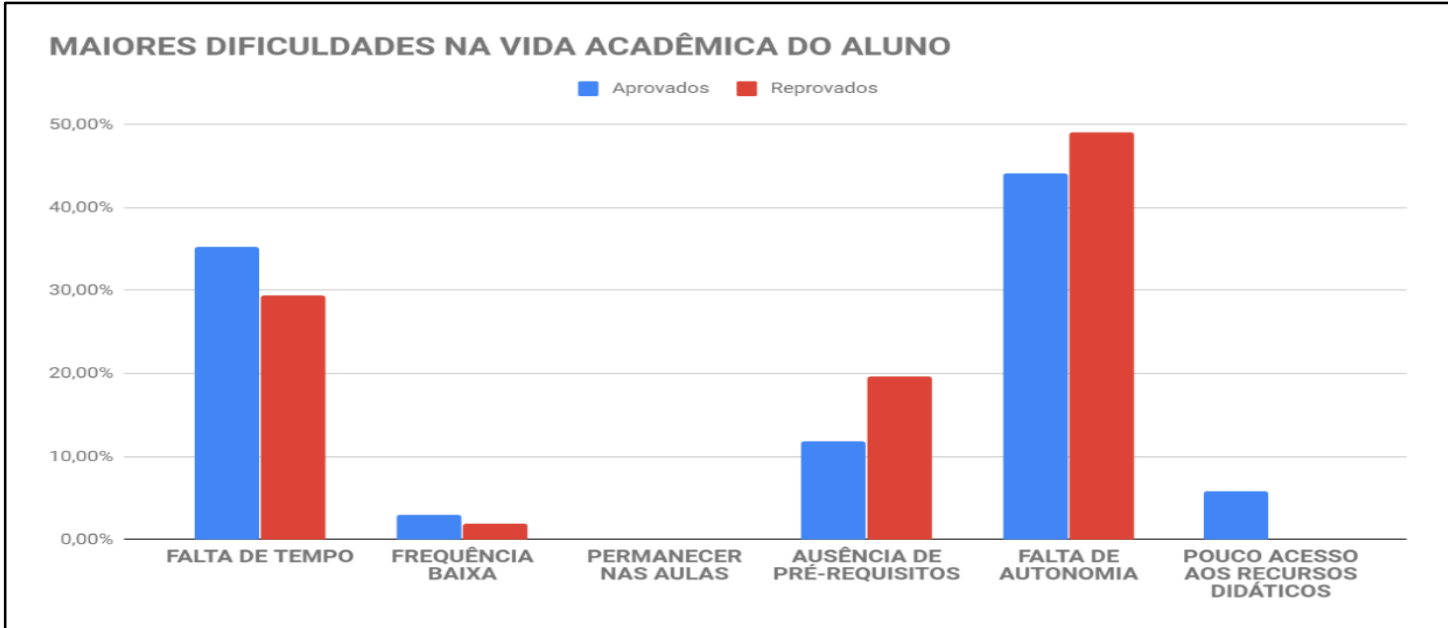

Fonte: Elaborado pelos autores (2020).

Figura 8 - Maiores dificuldades na vida acadêmica curso de Engenharia Elétrica.
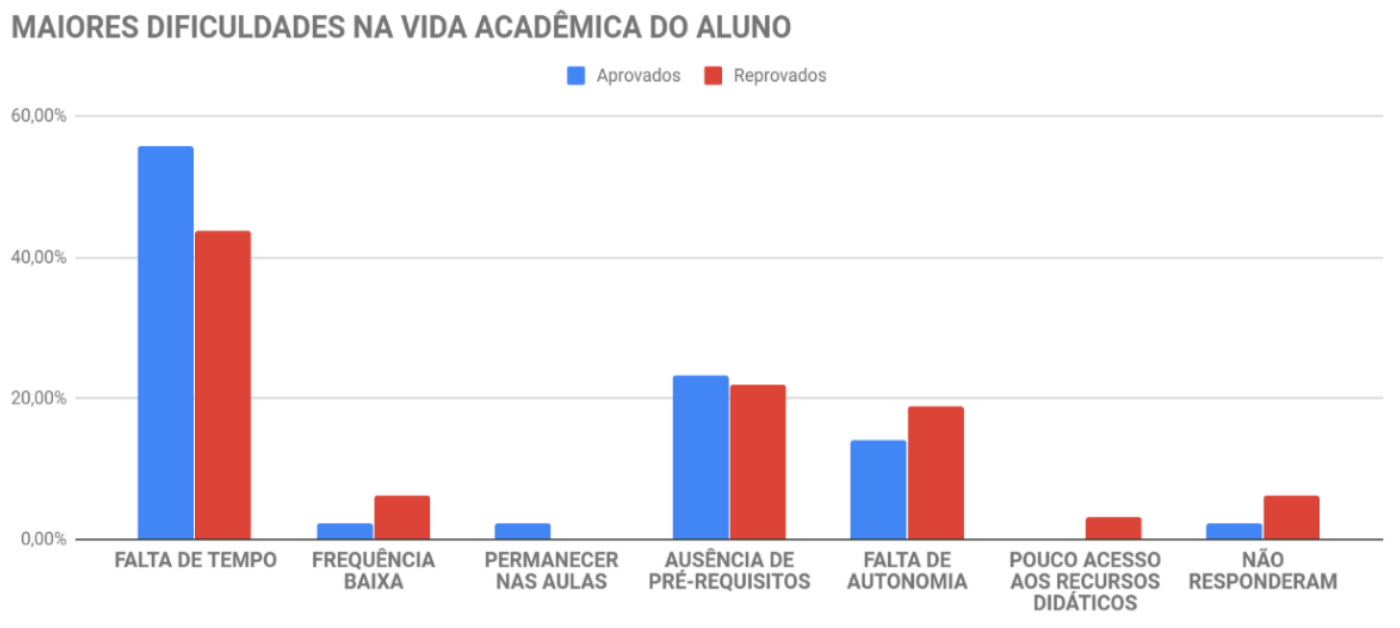

Fonte: Elaborado pelos autores (2020)

Figura 9 - Maiores dificuldades na vida acadêmica curso de Engenharia de Computação.

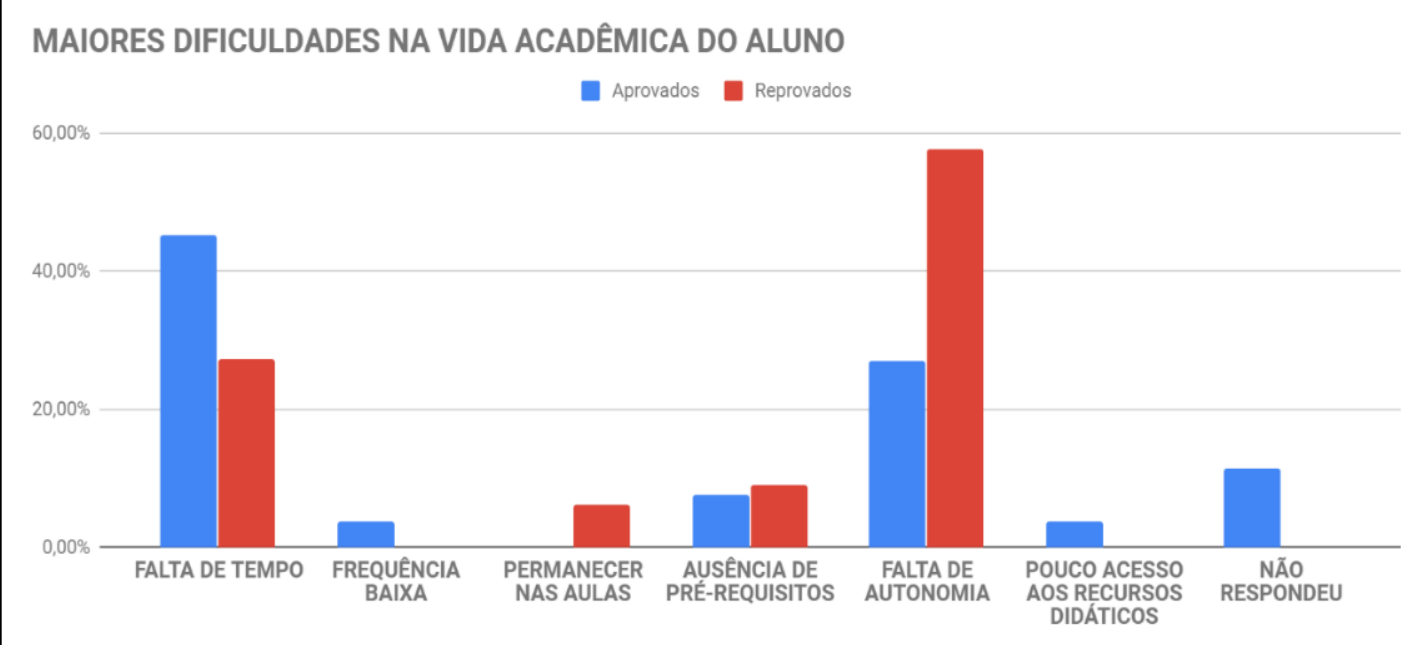

Fonte: Elaborado pelos autores (2020). 


\section{Evento On-line}

Um quantitativo maior de alunos, tanto aprovados quanto reprovados, nos três cursos, afirmou estudar acima de 5 horas por semana (Figuras 10, 11 e 12). Entretanto, é possível observar que a porcentagem de alunos que estuda mais de 5 horas semanais é maior no grupo de estudantes aprovados.

Figura 10 - Tempo de estudo semanal de alunos do curso de Engenharia de Controle e Automação.

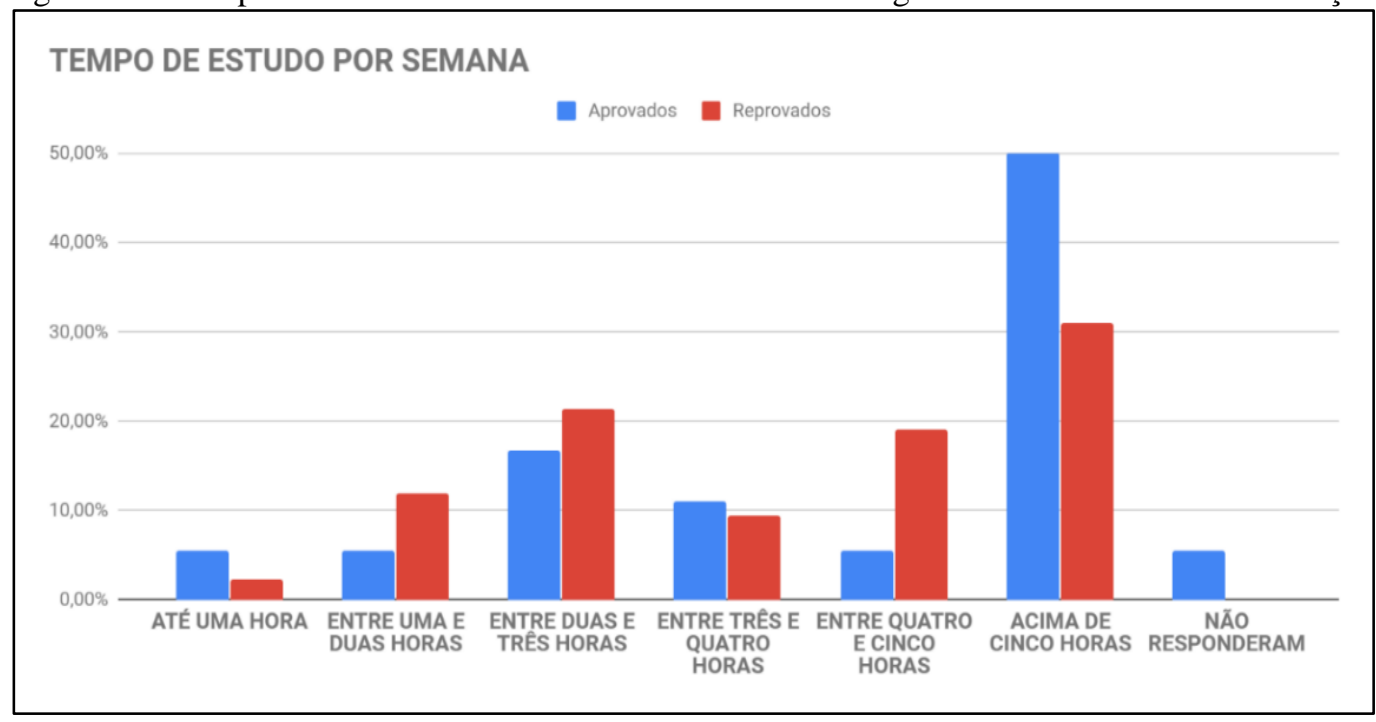

Fonte: Elaborado pelos autores (2020)

Figura 11 - Tempo de estudo semanal de alunos do curso de Engenharia Elétrica.

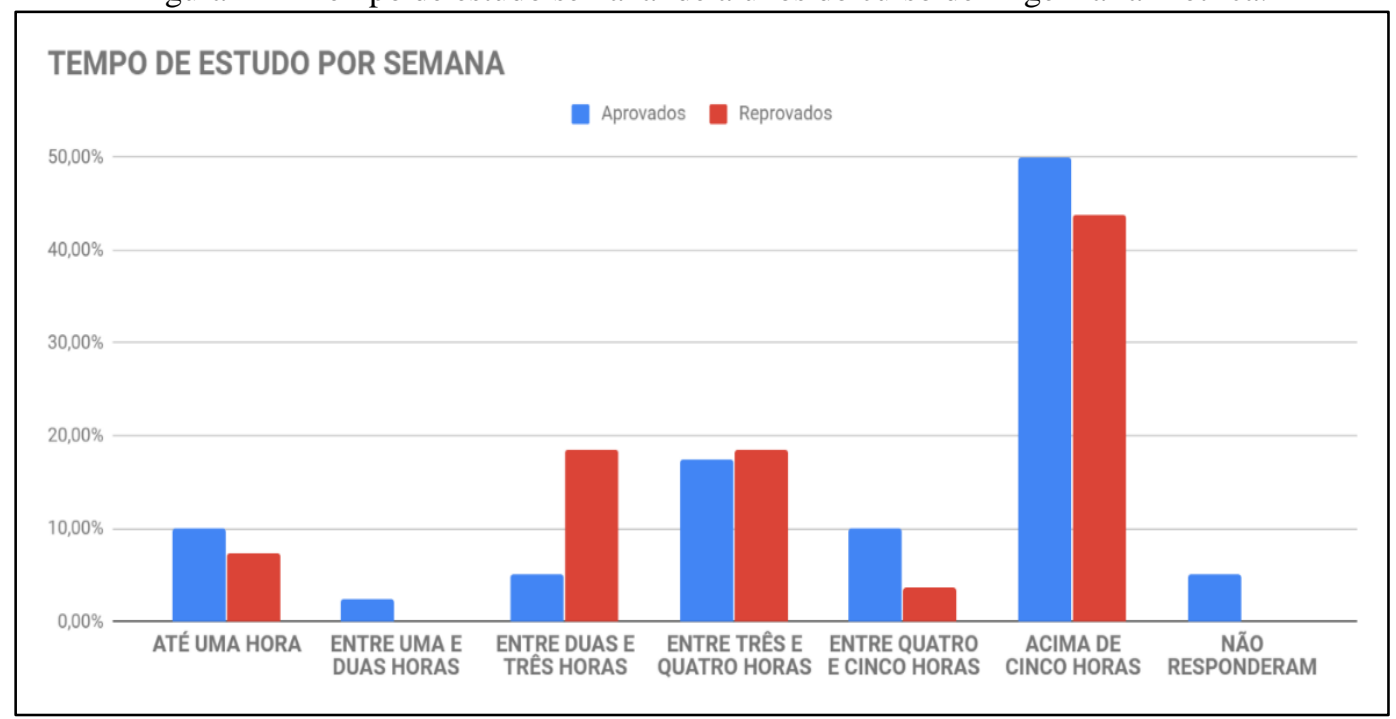

Fonte: Elaborado pelos autores (2020). 
Figura 12 - Tempo de estudo semanal de alunos do curso de Engenharia de Computação.

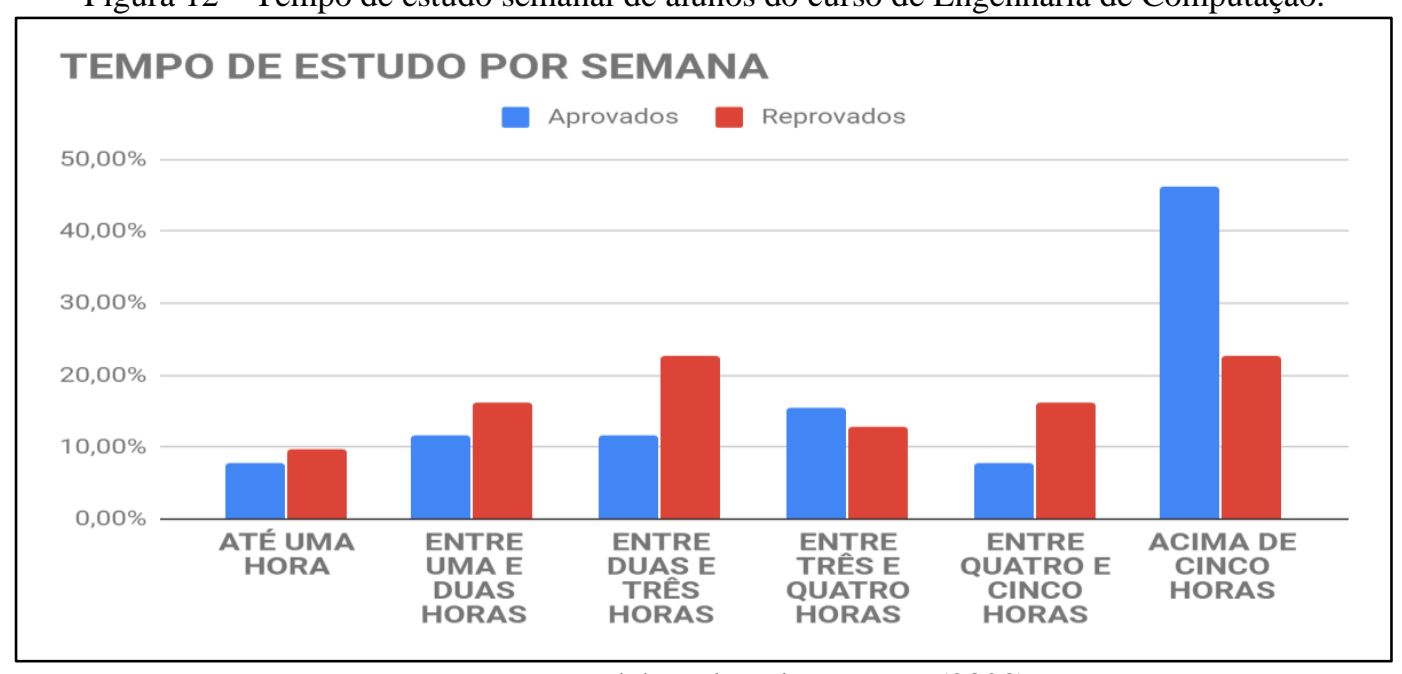

Fonte: Elaborado pelos autores (2020).

\section{CONSIDERAÇÕES FINAIS}

O estudo realizado mostra que a reprovação é um dos principais fatores da retenção. A reprovação, por sua vez, é causada por vários fatores que circundam o aluno. Logo, são necessárias ações diversas, as quais perpassam todos os atores da instituição (gestão, professor, aluno e família), para diminuir a taxa de reprovação e, consequentemente, a retenção.

Constata-se, nos três cursos pesquisados, que a carga horária de dedicação ao estudo é maior entre os alunos aprovados. Frente a esse fato, há a necessidade de se realizar um acompanhamento pedagógico para os alunos reprovados. O acompanhamento proposto deverá ter como finalidade a elaboração de estratégias que contribuam para uma melhor organização do tempo livre do discente para dedicação aos estudos.

Falta de tempo, falta de autonomia e ausência de pré-requisitos foram as maiores dificuldades apontadas pelos alunos em todos os cursos objeto do estudo. Nesse contexto, são necessárias intervenções pedagógicas que contribuam para que o discente possa desenvolver uma maior autonomia concernente ao hábito de estudar.

A proposta da criação de um programa de acolhimento e nivelamento do estudante, cujo objetivo é auxiliar na adaptação do aluno ao ensino superior, mostra-se necessária uma vez que fornece suporte acadêmico ao estudante, além de contribuir para superação de dificuldades préexistentes.

A monitoria é um instrumento já implementado nos cursos de engenharia no Instituto Federal Fluminense. Este instrumento oferece ao aluno um novo espaço e tempo de aprender. Entretanto, o programa de monitoria implementado carece de um contínuo aperfeiçoamento para atender aos alunos com maior eficiência. Este aperfeiçoamento deverá contemplar principalmente pesquisas com os alunos atendidos pela monitoria e análise frequente de dados de reprovação, sobretudo, nos períodos iniciais, a fim de inserir no programa de monitoria os componentes curriculares em que os discentes apresentem maiores dificuldade de aprendizagem.

Considerando que o professor é fundamental no processo de ensino e aprendizagem e que a metodologia de ensino adotada influencia no sucesso acadêmico do discente, torna-se essencial um programa permanente de capacitação docente a fim de que práticas didáticas contemporâneas sejam sempre aplicadas nos cursos de engenharia do Instituto Federal Fluminense. 


\title{
REFERÊNCIAS
}

AMARAL, João Batista do. Evasão discente no ensino superior: estudo de caso no Instituto Federal de Educação, Ciência e Tecnologia do Ceará (Campus Sobral). 2013. 48 f. Dissertação (Mestrado em Políticas Públicas e Gestão do Ensino Superior) - Superintendência de Recursos Humanos, Universidade Federal do Ceará, Fortaleza.

BRASIL. Ministério da Educação. Documento orientador para a superação da evasão e retenção na Rede Federal de Educação Profissional, Científica e Tecnológica. Brasília, 2014. 52p.

CISLAGHI, Renato. Um modelo de sistema de gestão do conhecimento em um framework para a promoção da permanência discente no ensino de graduação. 2008. 273 f. Tese (Doutorado em Engenharia e Gestão do Conhecimento), Universidade Federal de Santa Catarina, Florianópolis.

PLATAFORMA NILO PEÇANHA. Disponível http://resultados.plataformanilopecanha.org/2019/. Acesso em 03 de set. de 2019.

SILVA, Francisca Islandia Cardoso da; RODRIGUES, Janete de Páscoa; BRITO, Ahécio KleberAraújo. Retenção escolar no curso de educação física da Universidade Federal do Piauí. Educação em Perspectiva, Viçosa, v. 5, n. 2, p. 75-96, jul./dez. 2014.

TRIOLA, M. F. Introdução à Estatística. 10a edição. Rio de Janeiro: LTC, 2011.

\section{STUDY OF RETENTION AND REPROVAL INDEXES IN THE ENGINEERING COURSES OF CAMPUS CAMPOS CENTRO DO INFTITUTO FEDERAL FLUMINENSE}

\begin{abstract}
The present work presents the first results of a study on the retention of students in the Bachelor of Control and Automation Engineering, Electrical Engineering and Computer Engineering courses. The research aims to develop a methodology for evaluating and controlling the problem of retention (and therefore evasion) student of engineering at the Campos Centro campus of the Instituto Federal Fluminense. The instrument of this research in methodological support was a questionnaire prepared by a multidisciplinary team under laborious academic research. The statistical analysis of the database was descriptive. The study provided important discussions about the teaching and learning process of students, culminating in a proposal for actions that can support educational policies that contribute to greater academic success for students.
\end{abstract}

Keywords: Retention. Disapproval. Engineering. 